Purdue University Purdue e-Pubs

\title{
Toward informed leadership: Teaching students to make better decisions using information
}

Ilana Stonebraker

Purdue University, stonebraker@purdue.edu

Follow this and additional works at: http://docs.lib.purdue.edu/lib_fsdocs

Part of the Business Administration, Management, and Operations Commons, Information Literacy Commons, Organizational Behavior and Theory Commons, and the Strategic Management Policy Commons

\section{Recommended Citation}

Ilana Stonebraker (2016) Toward informed leadership: Teaching students to make better decisions using information, Journal of Business \& Finance Librarianship, 21:3-4, 229-238, DOI: 10.1080/08963568.2016.1226614

This document has been made available through Purdue e-Pubs, a service of the Purdue University Libraries. Please contact epubs@purdue.edu for additional information. 
Stonebraker 1

Towards Informed Leadership: Teaching Students to Make Better Decisions Using Information

Ilana Stonebraker

Purdue University 


\begin{abstract}
Studies have shown that introducing additional information without context leads to worse decision-making. Informed leadership is the purposeful integration of information into decision management. This paper reframes information literacy as decision management using elements of evidence- based management. It highlights strategies such as decision awareness, process creation, and decision practice, and approaches for purposeful application in the information literacy classroom.
\end{abstract}


Stonebraker 3

\section{Introduction- Access is Not Enough}

The 1983 report A Nation at Risk is often seen as sparking the modern information literacy movement. It proclaimed that "all, regardless of race or class or economic status, are entitled to a fair chance and to the tools for developing their individual powers of mind and spirit to the utmost" (Gardner, 1983, p. 5). From its very onset, the goal of information literacy efforts was "mature and informed judgement" as well as for Americans to "manage their own lives, thereby serving not only interests but also the progress of society itself' (quoted in Drabinski, 2014, p. 9). As librarians we are often great believers that information literacy is a transformative and elemental experience required for all citizens. Informed decision-making lies at the heart of the democratizing mission of information literacy.

In the spirit of this goal, librarians hope to create better decision-makers through instruction. While instruction objectives often includes critical thinking and use of quality information, one-shot instruction often focuses improving student performance on the particulars of database use. The aims of this database instruction is to infuse student projects with new, better information through practical advice. Yet adding new information, outside of the context of the decision or learning it creates, actually harms the decision-making process. Studies show that more information without the context of a meaning-making framework causes students to make decisions with increased overconfidence. Overconfidence impairs learning and decisionmaking. (Jones, 2014; Meehl, 1954). Information literacy instruction without context may boost database usage statistics, but it doesn't make students more informed leaders. Informed leadership requires a different approach.

The focus of this paper is to examine using informed leadership to reframe information literacy as decision management. First, I will introduce why teaching students information 
resource access and not teaching informed decision-making can create a less-, not moreinformed populace. Demonstrating access without informing context leads our patrons, students and stakeholders to make worse decisions. Secondly, I introduce a conceptual framework and research methodology (decision management) as a way to reframe information literacy education to improve decision-making, toward the ultimate goal of making our students as information literate as our democratizing mission aspires. As a possible method for implementing decision management in a management classroom, I will then explore evidence-based management as a structure for how to present an informed decision management model. Lastly, I will give examples and best practices from my own teaching that illustrate how informed leadership can be used to inform a business classroom.

Reframing information literacy as decision management and evidence-based practice has implications for how we introduce resources in the classroom environment. It is my hope that librarians can use this paper and its approach to reframe their instruction towards creating informed leaders of tomorrow.

\section{More is Worse: More Information Alone Does Not Lead to Better Decisions}

As statistician Nassim Nicholas Taleb stated in his book The Black Swan, information often proves to be toxic to decision management. "I've struggled much of my life with the common middlebrow belief that 'more is better'-more is sometimes, but not always, better" (Taleb, 2007, p. 145). In 1963, Oskamp studied clinical psychologist diagnostic capabilities. In the study, psychologists were supplied with excessive files, each containing an increasing amount of information about the patients. The study observed that "(a) their confidence about the case increases markedly and steadily but (b) the accuracy of their conclusions about the case quickly reaches a ceiling” (Oskamp, 1965, p. 261). This classic study has been cited over 1000 
Stonebraker 5

times. Overconfidence has been observed across clinicians (Miller, Spengler, \& Spengler, 2015), and in the stock market (Russo \& Schoemaker, 2002). The additional supply of information did not lead to better decisions, just overconfidence in their original decisions.

In a similar study on professional gambling, researchers asked bookmakers to select from 88 given variables in past horse races the five they found most useful in computing the odds. Variables included a variety of statistical information, including past performance. After they picked the variables, they made predictions based on them. The bookmakers were then given ten more variables and asked to predict again. The "increase in the information set did not lead to an increase in accuracy; their confidence in their choices, on the other hand, went up markedly" (As cited in Taleb, 2007, 145).

More information does not always have to lead to worse outcomes. Relying on human processing skills in unstructured, diverse domains, such as general education and management, is associated with worse outcomes as compared with those made with a systematic decisionmaking process. (Highhouse, 2008; Meehl, 1954; Rousseau, 2012). Information literacy has long been criticized as a form of research inoculation, an invented "social malady with which librarians as 'information professionals' are uniquely qualified to deal.” (Foster, 1993). The theory goes that if every student was exposed to scholarly research, they would be prepared to use those resources for the rest of their academic careers. In response, librarians have argued that their efforts address the changing needs of the American public and improve decision-making. In a talk given to library professionals, Zurkowski argued that in this new world where information "exceeds our capacity to evaluate it" information overload has become "a universal condition" (Zurkowski, 1974, p. 4). If we are truly in a world of information excess without context, it 
becomes even more important that we teach systematic decision-making to the public alongside searching skills.

\section{Decision Management, Evidence-based Management, Informed Leadership}

Yates defines decision management as the actions a person takes that affect how and how well the people on the scene (defined loosely by a variety of roles and responsibilities) make decisions (Yates, 2003). Decision-making is seen as a "fundamental human function, on par with other behaviors such as learning" (Yates \& Potworowski, 2012, p. 200). Decision-making is also a specific form of problem solving, one that emphasizes "aims of satisfying the personal interests and values of certain individuals, not people in general" (Yates \& Potworowski, 2012). The process of making decisions means isolating many different elements, including choices, evaluations, constructions (which are alternatives available only if specific options are chosen), and judgments.

Evidence-based management, or EBMgt, is one approach to decision management for librarians looking to adopt a decision management strategy in their classroom Evidence-based practice in general puts a pronounced emphasis on what is called "defensible evidence". According to Yates, these elements aid decision management in two ways: content and process. Content is information about the decision at hand, which aids in the creation of choices and construction. Process is the method in which a decision is reached, which appropriately weighs various aspects of the decision and potential constructions.

There are several issues with the full scale adoption of evidence-based practice into library instruction. Evidence-based management is helpful in terms of pedagogy because it joins 
decision management with information, but often takes an uncritical approach to information use. Relying on practices from medicine, systematic reviews and scholarly quantitative research hold special sway in this framework. By ignoring critics and privileging only specific types of research, EBMgt have:

missed the deeper point that some lines of research may just not be compatible with each other, because not only their methods but their underlying worldviews, assumptions, and even the language and jargon they use are so fundamentally different that they do not even share a common understanding of phenomena, concepts, and terminology." (Hornung, 2012, p. 384)

Along with issues of information use, evidence-based practices are often discipline-specific and therefore of less use for the general education course where librarians often teach. However, there are many lessons we can use from evidence-based management, especially as librarians are already active in the EBMgt field (Werner, 2012).

\section{Informed Leadership: Decision Management in Library Instruction}

\section{Decision Awareness, Process Creation, Decision Practice}

There are several ways that decision management can be integrated into library instruction. Some of these methods will resemble many library trends such as metaliteracy (Mackey \& Jacobson, 2010), critical information literacy (Elmborg, 2006), feminist library instruction (Accardi 2013), and active learning (Bonwell \& Eison, 1991; Detlor, Booker, Serenko, \& Julien, 2012). I will focus on three strategies from the evidence-based management education literature: decision awareness, process creation and decision practice.

Decision awareness asks students to identify different decisions they face and how different biases affect their decisions (Rousseau, "Denise Rousseau's Generic EBMgt Class 5 ", 2013). Some good examples can be found in the literature librarians can have students read before library instruction (Kahneman, Lovallo, \& Sibony, 2011). One activity I do in class is to 
have students read Before You Make That Big Decision and bring to class a decision they recently made as a group (see Appendix A). We then discuss various types of biases that might affect their decisions, such as attribution bias, which is the development of self-enhancing views of failures and successes. Another common bias is confirmation bias, where a student may only see things that agree with what they know already.

After we have discussed how day to day decisions are affected by bias, we then switch gears to discuss how scholars and experts might be affected by systematic bias. We discuss how the media might be biased. Students discuss a manager trying to implement a new technology and how they may be biased towards things that may make their life easier, but not the company. Lastly, in the next assignment, studentsexamine their own bias in their research process. What things could they have missed in their search and why? To some, decision awareness resembles many aspects of critical information literacy and feminist library pedagogy, which is intentional. Evidence-based management is the conscious slowing down of the process of decision-making in order to enable further reflection upon learning and engagement:

Being explicit means using information from each source in a clear, conscious and methodical way such that the roles played by all information in the final decision is understood. And being judicious involves using reflective judgement to evaluate the validity and relevance of the information from each source. Evidence and information is critical evaluated in relation to the practice context and problem (Briner \& Rousseau, 2011, p. 7)

In addition to new types of evidence, taking an informed approach to decision-making highlights not only the need for evidence itself, but the ways in decision-making requires "political awareness and political situational awareness" to understand the ways that decisions are a valueladen process rife with personal as well as systematic bias (Hodgkinson, 2012, p. 409).

Another informed leadership method is process creation. Students don't have a framework to break down decisions into elements, or realize they may need multiple frameworks 
Stonebraker 9

to break down decisions. That is why I try to show how someone should process the information they have in various ways. For example, I often show market research databases to entrepreneurs. As I do so, I make a SWOT (Strengths, Weaknesses, Opportunities, Threats) chart on the board for my example. As I find information I mark where I would put the information I found in the chart for an example. Is this statistic a strength for my idea? A weakness I should develop? A threat I should pivot on? Others may introduce K-W-L charts (KNOW, WANT to know, what they LEARNED) into their teaching to help students with process creation (Harada \& Tepe, 1998). Each time I introduce an example, I ask the class. What do we know? What do we want to know?

Teaching process creation is important because it shows many different methods that different disciplines use to make decisions with information. Critical information literacy often challenges librarians teaching students about the structures around them. Teaching process creation highlights that decision management, rather than occurring equivalently across academia, is actually a varied and nuanced process of combining together information and meaning.

Another element of informed leadership is repeated opportunities to practice integrating information into decisions. Students are very good at "hoarding" information, finding relevant articles or data, but they are often not as skilled at integrating that information into their decision-making processes. Therefore, I give students multiple opportunities to make recommendations based on what they have found using case studies in class. I call these activity CATs (Critical Appraised Topics, when done individually) or Group Challenges (when done in a group). An important element of decision management is that it goes beyond just the decision maker to the whole ecosystem of the decision affecter. So naturally decision practice could and 
should often be practiced in groups. In my course, students were presented with a case, which they broke down using a framework. They then had to find information to solve the stakeholder problem (see Appendix B). The students then present a recommendation, which uses the information they found. For example, if a market is competitive and companies are failing in large numbers, the student shouldn't recommend that a fledgling company enter it unless they have data to prove otherwise. Decisions should match decision information, or at acknowledge in time when students have consciously ignored some information and privileged others.

\section{One-Shot: Reframing the Information Need}

How, and when, to integrate informed leadership into an invited lecture format? Informed leadership can be used throughout a librarian's embedded practice. For example, when an instructor requests a session, a librarian may ask the instructor about the types of decisions that the students will have to make using the information resources presented. Is the faculty member looking to recommend a process to someone? Do students have to make a choice between two different options? This is a different approach than asking what the students need to learn from the resource. Often, learning from vendor-supplied library resources is more about the process than learning about any specific area or interface. Instructors often communicate to me that they don't really care about the databases themselves, or even that students find specific information. Rather, it is more about new types of decisions that the student can make when they have access to new information.

Inside of a one-shot environment, it is especially important in an informed leadership approach to do more than just show where to find information. From a decision management standpoint, introducing new information blindly could lead to decision neglect. Therefore, it is important to introduce a problem and associated decisions before teaching the resource, so that 
the student understands a context. In a classroom environment, this might be the assignment or perhaps a supplied case from the BYU Case Instruction Wiki (Spackman \& Camacho, 2009). The librarian then breaks down the problem into decisions that need validation. They then introduce the resource as one typically would, but with every new piece of information they read, they should synthesize that information in front of the class, so that students see that they shouldn't hoard information, but rather integrate the information with what they already know.

\section{Assessment Practices}

An important element of decision management and its assessment is defining what makes a better decision. Decision scientists are divided on the topic. There are many ways a decision may or may not serve the original intended stakeholders. A decision may be measured by the transparency of its process, or by the quality of outcomes (Yates \& Potworowski, 2012). Despite a large body of literature on information literacy learning, I could find no library literature on information literacy decision-making, or salient assessment metrics therein.

My assessment practices are emerging and largely qualitative and authentic. As

previously mentioned, informed leadership practices require an adjustment in the overall goals of assessment in the information literacy classroom from information knowledge to information use and decision-making. A student who shows informed leadership does not only know how to use quality resources, but rather should be able to exhibit all elements of a strong decision-making process. Previous assessment benchmarks such as increased confidence using resources and decreased library anxiety would not be good assessment of informed leadership. They should have the critical thinking ability to evaluate information, discover decisions that need to be made using the information, find information needed, and then incorporate the information into their 
decision-making processes, not once but multiple times. Evidence that students know how to do one step, like access information or cite correctly, is not evidence of informed leadership skills.

\section{Conclusion}

To some, the inability of students to integrate information into their decisions without context will come as no surprise. The ACRL Framework for Information Literacy for Higher Education defined information literacy not as skills but as a "set of integrated abilities encompassing the reflective discovery of information" (Association of College \& Research Libraries, 2015, p. 3). The Framework stressed "research as inquiry" which includes knowledge practices such as the ability to formulate questions, determine scope of investigation, and organized information in "meaningful ways" (Association of College \& Research Libraries, 2015 , p. 7). Learning in context is increasingly important in the new framework, where skills are contextualized into scholarly environments. Informed leadership is a more structured method to help students develop these skills for other decision contexts outside the scholarly environment.

As Rousseau pointed out "[i]n the past decade, we have seen very smart executives make big mistakes because they didn't understand the context in which they were operating" (Rousseau, 2012, 9). More than ever, responsible information use is key to the survival of top companies. At the same time, information literacy has deeper roots in higher education than ever before. A recent ACRL study has found from assessment projects at over 200 institutions that library instruction increases student success, strengthens general education outcomes, and improves student course performance (Association of College \& Research Libraries, 2016). 
Teaching information access is not enough. Work still needs to be done to make students true informed leaders. In this paper, I have outlined issues with traditional one-shot instruction in terms of teaching decision management. I have highlighted some solutions from the decision management and evidence-based management literature. Decision awareness, process creation, and decision practice are potential strategies, as well as reframing one-shot environments. As information literacy grows as a discipline and a university objective, we as librarians must work towards informed leadership in our information literacy instruction to teach students to make better decisions using information.

\section{References}

Accardi, Maria T. Feminist pedagogy for library instruction. 2013. Library Juice Press.

Association of College \& Research Libraries. (2015). ACRL Information Literacy Framework for Higher Education.

Association of College \& Research Libraries. (2016). Documented Library Contributions To Student Learning and Success. Retrieved April 27, 2016, from http://www.ala.org/acrl/sites/ala.org.acrl/files/content/issues/value/contributions_y2.pdf

Bonwell, C. C., \& Eison, J. A. (1991). Active Learning: Creating Excitement in the Classroom. 1991 ASHE-ERIC Higher Education Reports. ERIC.

Briner, R. B., \& Rousseau, D. M. (2011). Evidence- based I-O psychology: Not there yet. Industrial and Organizational Psychology, 4(1), 3-22.

Detlor, B., Booker, L., Serenko, A., \& Julien, H. (2012). Student perceptions of information literacy instruction: The importance of active learning. Education for Information, 29(2), 147-161. Retrieved from http://search.ebscohost.com/login.aspx?direct=true $\& d b=e u e \& A N=80731478 \&$ site=ehostlive

Drabinski, E. (2014). Toward a Kairos of Library Instruction. The Journal of Academic Librarianship, 40(5), 480-485. doi:10.1016/j.acalib.2014.06.002

Elmborg, J. (2006). Critical Information Literacy: Implications for Instructional Practice. The Journal of Academic Librarianship, 32(2), 192-199. doi:10.1016/j.acalib.2005.12.004

Foster, S. (1993). Information Literacy: Some Misgivings. American Libraries, 24(4), 344-346. Retrieved from http://www.jstor.org.ezproxy.lib.purdue.edu/stable/25632883 
Gardner, D. P. (1983). A nation at risk. Washington, DC: The National Commission on Excellence in Education, US Department of Education.

Harada, V., \& Tepe, A. (1998). Pathways to knowledge [Information literacy standards for student learning]. Teacher Librarian, 26(2), 9.

Highhouse, S. (2008). Stubborn reliance on intuition and subjectivity in employee selection. Industrial and Organizational Psychology, 1(3), 333-342.

Hodgkinson, G. P. (2012). The politics of evidence-based decision making. The Oxford Handbook of Evidence-Based Management, 404-418.

Hornung, S. (2012). Beyond "New Scientific Management" Critical reflections on the epistemology of evidence-based management. The Oxford Handbook of Evidence-Based Management, 389-403.

Jones, R. C. (2014). Making Better (Investment) Decisions. Journal of Portfolio Management, 40(2), 17,128-143. Retrieved from http://search.proquest.com/docview/1496996059?accountid=13360

Kahneman, D., Lovallo, D., \& Sibony, O. (2011). Before you make that big decision. Harvard Business Review, 89(6), 50-60.

Mackey, T. P., \& Jacobson, T. E. (2010). Reframing Information Literacy as a Metaliteracy. College \& Research Libraries . Retrieved from http://crl.acrl.org/content/early/2010/04/29/crl-76r1.abstract

Meehl, P. E. (1954). Clinical versus statistical prediction: A theoretical analysis and a review of the evidence.

Miller, D. J., Spengler, E. S., \& Spengler, P. M. (2015). A meta-analysis of confidence and judgment accuracy in clinical decision making. Journal of Counseling Psychology. Miller, Deborah J.: Department of Counseling Psychology and Guidance Services, Ball State University, Muncie, IN, US, 47306, debmillerphd@gmail.com: American Psychological Association. doi:10.1037/cou0000105

Oskamp, S. (1965). Overconfidence in case-study judgments. Journal of Consulting Psychology. US: American Psychological Association. doi:10.1037/h0022125

Rousseau, D. (2013, June 26). Denise Rousseau's Generic EBMgt Class 5. Retrieved April 26, 2016, from http://www.slideshare.net/barene/denise-rousseaus-generic-ebmgt-class-5/1

Rousseau, D. M. (2012). Envisioning evidence-based management. The Oxford Handbook of Evidence-Based Management, 3-24.

Russo, J. E., \& Schoemaker, P. J. H. (2002). Winning decisions: Getting it right the first time. Crown Business.

Smith, J. L. (2015). Feminist Pedagogy for Library Instruction. Reference \& User Services Quarterly, 54(3), 53-54.

Spackman, A., \& Camacho, L. (2009). Rendering information literacy relevant: A case-based pedagogy. The Journal of Academic Librarianship, 35(6), 548-554.

Taleb, N. N. (2007). The black swan: The impact of the highly improbable. Random House.

Werner, R. (2012). Buried Treasure: A Business Librarian's Insights on Finding the Evidence. 
Stonebraker 15

Yates, J. F. (2003). Decision management: How to assure better decisions in your company (Vol. 29). John Wiley \& Sons.

Yates, J. F., \& Potworowski, G. A. (2012). Evidence-based decision management. The Oxford Handbook of Evidence-based Management, 716-790.

Zurkowski, P. G. (1974). The Information Service Environment Relationships and Priorities. Related Paper No. 5. 


\section{Appendix A: Checking Biases Over Spring Break Assignment}

The reading "Before You Make that Big Decision" is all about checking biases and pitfalls when making business decisions. But it applies to every day decisions as well.

Pick a type of bias mentioned in the article (self-interested bias, affect heuristic, groupthink, cost fallacy, endowment effect, disaster effect, loss aversion, overconfidence, planning fallacy, optimistic bias, competitor neglect, etc).

Over spring break or the week after spring break, look for a time in which you made a decision you made with a group that may have been affected by this bias. Describe that situation below, and how that bias affected that decision (minimum 150 words).

Bring your situation to class Wednesday (either on paper or in your head) to discuss. 


\section{Appendix B: Group Challenge Using Scholarly and Trade Journal Articles}

DUE: End of class today, to Blackboard. This is a group project that will be graded for overall accuracy, following directions and completion. Put the name of your group members present in the comment box when you submit to Blackboard. Problems submitting to Blackboard? Email me your assignment: stonebraker@ purdue.edu

This is a group assignment that will be graded on its merits. Three of the points will be for accuracy and ability to follow directions, five points for the quality of the recommendation using the information, one point for grammar and spelling, and one point for clarity.

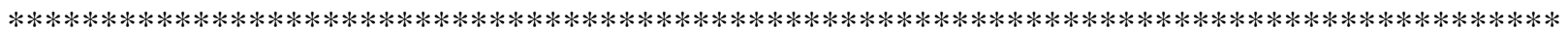

You work for a successful furniture manufacturer located in the Midwest. You have recently found out that 14,000 of the baby cribs you manufacturer were deemed unsafe by the Consumer Product Safety Commission. There is a risk of an entrapment hazard, meaning babies can fall becoming entrapped in the crib bars, or suffer cuts. You need to issue a voluntary recall so that you can give your customers a free (safer) replacement mattress support with newer brackets. In order to avoid large publicity issues, you need to recall these baby cribs in a short amount of time.

You are on the team to research potential solutions for implementing the recall in the short amount of time. Your team has decided to research two forms of evidence to help decide how to recall the cribs in the fastest manner. First you are going to research three companies (IKEA, Bexco and Playkids USA) who have done recent recalls. Second, you will locate a scholarly approach to reverse logistics, recall management or product recalls for best practices. For this case, you are most interested in doing the recall most efficiently and effectively.

Suggested way of breaking the project up

10:30-11: One group member works on finding the scholarly journal article. Three student work on locating the three recent events and writing up the paragraph summary. As the Question 1 students finish they check each other's work. You may also want to put an additional person on finding/reading the scholarly article.

11:05-11:10: Bring all information together and discuss what you think the company should do. 11:10-11:20: Write up two paragraph response. Submit.

\section{Questions to answer as a team}

1) Use either ABInform or Business Source Premier to locate three recent (within last six years) recall events involving IKEA, Bexco, and Playkids USA. Summarize them briefly (1-2 sentences each) and then describe how all of them would affect your recall (1 paragraph).

2) Use either ABInform or Business Source Premier to locate one article which might be a good model for you to consider when implementing the recall.

It does not need to be about baby cribs or furniture but does need to be written in the last 12 years. This article could answer any (but does not need to answer all) of the following questions: logistics?

How do companies maximize the efficiency of their supply chains when implementing reverse

What are the most effective reverse logistics systems?

How do you write the most effective product recall message to get people to participate? 
How does someone plan and implement a successful product recall?

What are factors affecting implementation of reverse logistics?

What frameworks do scholars use when they study reverse logistics?

Summarize your article briefly and how they might help you in your decision (1 paragraph)

3) Based on your answers above, what do you think your company should do? Were any of the three companies using a model you would follow? Did your scholarly article point to any specific things your group should consider when implementing the recall? Support your decision with information from your articles and summaries ( 2 paragraphs)

4) In all, you will have located four articles. Please give the citations for the articles 